\title{
Impact of epidural labor analgesia using sufentanil combined with low-concentration ropivacaine on maternal and neonatal outcomes: a retrospective cohort study
}

Le Zhang ${ }^{\dagger}$, Chengjie Xu and Yue Li ${ }^{* \dagger}$

\begin{abstract}
Background: Whether epidural administered sufentanil combined with low-concentration ropivacaine affected labor progress as well as maternal and neonatal outcomes still remained unknown. The aim of this study was to assess the impact of epidural sufentanil plus ropivacaine on maternal and neonatal outcomes.

Methods: This is a retrospective cohort study. Data of singleton full-term pregnancy women who received epidural labor analgesia for vaginal delivery from May 2018 to June 2020 were collected. Parturients were divided into two groups (the R group and the SR group) according to different medication regimens for epidural labor analgesia. The implementation of epidural analgesia during labor was performed with $0.167 \%$ ropivacaine in the R group and $0.1 \%$ ropivacaine in combination with $0.5 \mu \mathrm{g} / \mathrm{ml}$ sufentanil in the SR group. The primary outcome of our study included the duration of labor progress and the incidence of maternal fever, postpartum hemorrhage, fetal distress and neonatal Apgar scores less than 7 at 1 and $5 \mathrm{~min}$. The secondary outcome included the incidence of episiotomy, instrumental delivery, caesarean section and grade III meconium-stained amniotic fluid.
\end{abstract}

Results: There were a total 3778 deliveries during the study period, 1994 and 1784 parturients were included in the $R$ group and in the SR group, respectively. The length of the first stage of labor was remarkably shorter in the R group in comparison to the SR group (548.0 \pm 273.0 vs. $570.9 \pm 273.0, P=0.013)$. No significant difference was found in the incidence of maternal fever, postpartum hemorrhage, fetal distress and in the neonatal Apgar scores less than 7 at 1 and 5 min between two groups. Other Maternal outcomes were comparable in the R group and the SR group.

Conclusions: $0.5 \mathrm{\mu g} / \mathrm{ml}$ sufentanil plus $0.1 \%$ ropivacaine for epidural labor analgesia prolonged the duration of the first stage of labor, but did not have additional impact on maternal and neonatal outcomes compared with the sole $0.167 \%$ ropivacaine.

Trial registration: Clinical Research Information Service with registration number ChiCTR2100045162. Registered 7 April 2021.

Keywords: Epidural labor analgesia, Labor progress, Maternal outcomes, Neonatal outcomes

*Correspondence: 13918324826@163.com

†Le Zhang and Yue Li contributed equally to this work. Department of Anesthesiology, Obstetrics and Gynecology Hospital

of Fudan University, 419 Fangxie Road, Shanghai 200011, China

\section{Background}

Epidural analgesia with local anesthetics such as ropivacaine was considered as an effective way to relieve the pain of uterine contraction [1-3]. However, some studies $[4,5]$ have shown that a relatively high total dosage original author(s) and the source, provide a link to the Creative Commons licence, and indicate if changes were made. The images or other third party material in this article are included in the article's Creative Commons licence, unless indicated otherwise in a credit line to the material. If material is not included in the article's Creative Commons licence and your intended use is not permitted by statutory regulation or exceeds the permitted use, you will need to obtain permission directly from the copyright holder. To view a copy of this licence, visit http://creativecommons.org/licenses/by/4.0/. The Creative Commons Public Domain Dedication waiver (http://creativeco mmons.org/publicdomain/zero/1.0/) applies to the data made available in this article, unless otherwise stated in a credit line to the data. 
of local anesthetic may have an effect on uterine activity by decreasing the rate and strength of the uterine contraction.

Moreover, local anesthetics were more likely associated with epidural-related maternal fever via a number of ways of immunomodulation [6,7] and cell injury [8]. Thus, epidural administered local anesthetic might potentially cause complications on both maternal and neonatal outcomes time-dependently and dose-dependently. Epidural opioids was also recommended and commonly used in combination with local anesthetics to reduce the dose of local anesthetics and to provide equal, if not superior analgesic effect [9]. Wang et al. reported that ropivacaine with sufentanil for labor analgesia provided effective analgesic effect without significant side effects and delay of the labor progress [10]. But in a recent meta-analysis [11], sufentanil in combination with bupivacaine was considered to be associated with worse neonates Apgar score.

In our institution, as a regular protocol, epidural labor analgesia is conducted using either $0.167 \%$ ropivacaine or $0.1 \%$ ropivacaine in addition to $0.5 \mu \mathrm{g} / \mathrm{ml}$ sufentanil. Although both of them provided almost the equivalent analgesic effects, whether the combination epidural sufentanil and low-concentration ropivacaine will affect the labor progress as well as maternal and neonatal outcomes, as the single usage of high-dose local anesthetic, still remained controversial.

Therefore, we performed a retrospective cohort study to observe women who received $0.167 \%$ ropivacaine alone vs. sufentanil with $0.1 \%$ ropivacaine for epidural labor analgesia to assess the impact of the combination of sufentanil and ropivacaine on both maternal and neonatal outcomes.

\section{Methods}

This retrospective group study was approved by the institutional review board from the Obstetrics and Gynecology Hospital of Fudan University and was registered at the Clinical Research Information Service (ChiCTR2100045162, Principal investigator: Yue Li). Informed consent of information collection for research was obtained from all participants. All the study methods were carried out in accordance with the combination of our institutional regulations and guildlines. The study adheres to the ethical standards of the Declaration of Helsinki (1964) and its subsequent amendments.

Medical records were retrospectively reviewed from May 2018 to June 2020, singleton full-term pregnancy women who received epidural labor analgesia via vaginal delivery were included in the study. Women with severe systemic disease that results in functional impairment (American Standards Association, ASA $\geq$ III) or fetal dysplasia were excluded from the cohort. Parturients were classified into two groups: women who received $0.167 \%$ ropivacaine alone (the $\mathrm{R}$ group) and women who received sufentanil with $0.1 \%$ ropivacaine (the SR group) according to different medication regimens for epidural labor analgesia by provider preference. Both regimens were administered via an epidural analgesia pump in a patient-controlled analgesia manner, $8 \mathrm{ml} / \mathrm{h}$ epidural analgesic with $0.167 \%$ ropivacaine or $0.1 \%$ ropivacaine in combination with $0.5 \mathrm{ug} / \mathrm{ml}$ were administered in the $\mathrm{R}$ group or the SR group, respectively. The patient-controlled bolus was set to deliver a dosage of $8 \mathrm{ml}$ of analgesics with a lockout interval of $15 \mathrm{~min}$.

Demographic characteristics were collected, including the maternal age, gestational weeks, parity in the gravidae, body mass index (BMI), whether the mother underwent induced labor, presence of pregnancy comorbidities, and neonatal birth weight.

The primary outcome of the present study was the duration of labor progress. The duration of labor progress collected in our study included three stages. The first stage of labor was defined as time from diagnosis of labor to full dilatation of the cervix. The second stage of labor was defined as time from full dilatation of cervix to delivery of the fetus and the third stage of labor was time from delivery of the fetus to delivery of the placenta. The secondary outcome included the incidence of maternal fever, postpartum hemorrhage, fetal distress, episiotomy, instrumental delivery, caesarean section, grade III meconium-stained amniotic fluid (MSAF) and neonatal outcome (Apgar scores $<7$, at 1 and $5 \mathrm{~min}$, respectively). Maternal fever was defined as the body temperature $>38^{\circ} \mathrm{C}$. Postpartum hemorrhage was defined as estimated blood loss $\geq 500 \mathrm{ml}$ after delivery of the placenta. Fetal distress was diagnosed by the obstetricians and their Apgar scores were assessed by neonatologists after vaginal deliveries and cesarean deliveries. All these demographic information and obstetric outcomes were collected from the electronic medical record system of our hospital.

\section{Statistical analysis}

Statistical analysis was performed using SPSS 20.0 (SPSS, Inc., Chicago, IL, USA) and GraphPad Prism 5.01 software (GraphPad Inc., CA, USA). The duration of three stages of labor were presented as mean \pm standard deviation (SD). Neonatal outcomes, incidences of maternal fever, postpartum hemorrhage, instrumental delivery, conversion to caesarean section, postpartum hemorrhage the use of episiotomy and the presence of grade III MSAF were presented as percentage. Continuous variables were analyzed using $\mathrm{t}$ test, and categorical variables were 
analyzed using Chi-Square test. Statistical significance was set at $P<0.05$.

\section{Results}

According to the inclusion criteria, a total of 3778 deliveries during the study period were retrospectively reviewed, with 1994 parturients in the $\mathrm{R}$ group and 1784 parturients in the SR group. The demographic characteristics including the maternal age, BMI, gestational weeks, rate of multiparous and complications, oxytocin induction and neonatal birth weight did not demonstrate significant differences between the $\mathrm{R}$ group and the SR group $(P>0.05)$ (Table 1$)$.

As shown in Table 2, the duration of the first stage of labor wassignificantly shorter in the $\mathrm{R}$ group in comparison to the SR group (548.0 $\pm 273.0 v s .570 .9 \pm 273.0$, $P=0.013)$. Nosignificant difference was detected in the duration of the second stage of laborand the third stage of labor between the two groups $(P>0.05)$. The incidence of maternal fever, postpartumhemorrhage, episiotomy, instrumental delivery, conversion to caesarean section, and grade III MSAF also had no statistical significance between the two groups $(P>0.05)$.

For neonatal outcomes (Table 3), the incidence of fetal distress demonstrated no statistical significance between the $\mathrm{R}$ group and the SR group. There was no significant difference for the Apgar score between the two groups at 1 and $5 \mathrm{~min}$ as well.

\section{Discussion}

Epidural administered ropivacaine and sufentanil has been a common protocol used in labor analgesia $[12,13]$. Adding sufentanil to ropivacaine can effectively enhance the analgesia effect [14] and thus reduce the consumption of the local anesthetics. However there are concerns of the opioids-related adverse effects on the labor progress as well as maternal and neonatal outcomes [15].

Table 1 Demographic characteristics of study population. Data reported as mean \pm SD and $\mathrm{N}(\%)$

\begin{tabular}{llll}
\hline & $\mathbf{R}(\boldsymbol{n}=\mathbf{1 9 9 4})$ & $\mathbf{S R}(\boldsymbol{n}=\mathbf{1 7 8 4})$ & $\boldsymbol{P}$ \\
\hline Maternal age (y) & $29.77 \pm 3.93$ & $30.04 \pm 3.99$ & 0.103 \\
BMl & $26.85 \pm 3.287$ & $26.59 \pm 3.176$ & 0.117 \\
Gestational weeks & $39.29 \pm 1.051$ & $39.33 \pm 1.086$ & 0.158 \\
Multiparous & $233(13.2)$ & $252(12.5)$ & 0.507 \\
Complications & $488(27.7)$ & $533(26.4)$ & 0.385 \\
Oxytocin induction & $752(37.7)$ & $698(39.1)$ & 0.373 \\
Birth weight(g) & $3377 \pm 394.9$ & $3381 \pm 407.5$ & 0.605 \\
\hline
\end{tabular}

$P$-value is compared between the $\mathrm{R}$ group and the $\mathrm{SR}$ group

$y$ Year, BMI Body mass index, $g$ Gram
Table 2 Labor progress and maternal outcomes. Data reported as mean \pm SD and $\mathrm{N}(\%)$

\begin{tabular}{|c|c|c|c|}
\hline & $\mathrm{R}(n=1994)$ & $\mathrm{SR}(n=1784)$ & $P$ \\
\hline \multicolumn{4}{|l|}{ Labor progress } \\
\hline 1st stage (min) & $548.0 \pm 273.0$ & $570.9 \pm 273.0$ & $0.013^{*}$ \\
\hline 2nd stage (min) & $68.51 \pm 50.36$ & $66.61 \pm 55.25$ & 0.082 \\
\hline 3rd stage (min) & $5.36 \pm 3.16$ & $5.29 \pm 3.34$ & 0.112 \\
\hline Maternal fever & $451(22.62)$ & $412(23.09)$ & 0.728 \\
\hline Postpartum hemorrhage & 78 (3.91) & $74(4.15)$ & 0.712 \\
\hline Episiotomy & $896(51.41)$ & $755(48.27)$ & 0.072 \\
\hline Instrumental delivery & $193(11.07)$ & $187(11.96)$ & 0.426 \\
\hline Caesarean section & $251(12.5)$ & $220(12.3)$ & 0.812 \\
\hline Grade III MSAF & $417(20.91)$ & $377(21.13)$ & 0.869 \\
\hline
\end{tabular}

min Minute, MSAF Meconium-stained amniotic fluid

*Statistical significance of difference between the $\mathrm{R}$ group and the SR group $(P<0.05)$

In our study, the average duration of the first stage of labor was significantly lower in the $0.167 \%$ ropivacaine group than the $5 \mu \mathrm{g}$ sufentanil $+0.1 \%$ ropivacaine group. This was similar in several clinical studies [16, 17] which found that women with opioids analgesia had a prolonged duration of labor. Some animal studies also showed that opioids can affect spontaneous contraction of uterine musclature $[18,19]$. It seems to be possible that the delay of labor progress could be partly attributed from the inhibiting effect of opioids on uterine contractility. However, a study about the effects of opioids on isolated human pregnant uterine muscles demonstrated that fentanyl and morphine inhibited spontaneous contraction of the uterine muscle, while sufentanil did not [20]. The mechanism of the inhibitory potency of opioids was not yet clear. It was believed that the inhibitory effect of opioids was not mediated through the opioid receptors. Since the dosage of the opioids used on the isolated human uterine muscles was far more than the regular clinical doses, it is somewhat unclear that the clinical doses of opioids can be the culprit prolongs the labor progress with clinical significance or increases the risk of postpartum hemorrhage by decreasing the uterine contractility. In accordance to our study, although the first

Table 3 Adverse neonatal outcomes. Data reported as N (\%)

\begin{tabular}{lrrr}
\hline & $\mathbf{R}(\boldsymbol{n}=\mathbf{1 9 9 4})$ & $\mathbf{S R}(\boldsymbol{n}=\mathbf{1 7 8 4})$ & $\boldsymbol{P}$ \\
\hline Fetal distress & $231(11.58)$ & $228(12.78)$ & 0.262 \\
Apgar score & & & \\
1 min Apgar score $<7$ & $34(1.71)$ & $33(1.85)$ & 0.737 \\
5 min Apgar score $<7$ & $3(0.15)$ & $3(0.17)$ & 0.891 \\
\hline
\end{tabular}


stage of labor was longer in the sufentanil combination group, the statistical significance between the two groups was not clinically important $(9 \mathrm{~h}$ and $8 \mathrm{~min}$ vs. $9 \mathrm{~h}$ and $30 \mathrm{~min}$ ) and the incidence of postpartum hemorrhage was shown to have no difference between the two groups. Moreover, there was no difference in the incidence of maternal fever, postpartum hemorrhage, episiotomy, instrumental delivery, caesarean section and grade III MSAF. Regarding the maternal outcomes, the combination of $0.1 \%$ ropivacaine and $5 \mu \mathrm{g} /$ $\mathrm{ml}$ sufentanil for epidural labor analgesia was not able to bring advantages or disadvantages in comparison to $0.167 \%$ ropivacaine.

Other than that, neonatal outcomes were also demonstrated no significant difference between the two groups, which wasn't fully compliant to the study with Wang et al. [21]. In their study, it was found that the sole local anesthetic ropivacaine had less incidence of poor Apgar scoring at $1 \mathrm{~min}$ than the combination of ropivacaine and sufentanil, which could be resulted from the low concentration of ropivacaine in the SR group in our study. In some previously published prospective studies comparing the impact of opioids in labor analgesia, the concentration of the local anesthetics in the intervention group and the control group were usually the same, in order to isolate and clearly identify the effect of the opioids administration. But in clinical scenarios, we found that the addition of sufentanil was able to reduce the dosage of ropivacaine almost by half, which provided comparable analgesic effect. Therefore, in the present study, the concentration of ropivacaine in the SR group was lower than the $\mathrm{R}$ group. What we actually retrospectively reviewed and compared was two different therapeutic regimens in management of labor pain. Similar to the findings from several studies [22-24], our results showed that $0.5 \mu \mathrm{g} /$ $\mathrm{ml}$ sufentanil plus $0.1 \%$ ropivacaine had no influence on neonatal outcomes.

There were several limitations in our study. First, the dosage of oxytocin, the incidence of fetal hypoxia and admission to the neonatal intensive care unit (NICU) and maternal adverse effects such as vomiting and pruitus could not be collected due to limited to available data. Secondly, the medication regimens for epidural labor analgesia were commonly used in our single institution, which might not be popularized entirely to other institutions with various labor analgesia managements. And it is difficult to come to a conclusion that any differences we found in our study is simply resulted from the addition of sufentanil. Lastly, the data of this retrospective study were collected from the electronic medical record, which made it somewhat challenging to confirm the exactitude.

\section{Conclusions}

In conclusion, in this retrospective study, an epidural infusion of $0.1 \%$ ropivacaine $+0.5 \mu \mathrm{g} / \mathrm{ml}$ sufentanil was associated with a longer duration of 1st stage of labor than an epidural infusion of $0.167 \%$ ropivacaine, but did not have additional impact on either maternal or neonatal outcomes.

\section{Abbreviations \\ ASA: American Standards Association; BMI: Body mass index; MSAF: Meco- nium-stained amniotic fluid; SD: Standard deviation; NICU: Neonatal intensive care unit. \\ Acknowledgements \\ Thanks are due to Xirong Xiao and Xiaochun Zhao for valuable discussion. \\ Authors' contributions \\ Le Zhang had contribution to analysis of data and drafting the article. ChengjieXu had contribution to acquisition of data. Yue Li had contribution to conceptionand design, revising it critically for important intellectual content, and finalapproval of the version to be published. All authors discussed the results andcommented on the manuscript. The author(s) read and approved the final manuscript. \\ Funding \\ None of the authors received any funding to support this work.}

\section{Availability of data and materials}

The datasets generated and analyzed during the current study are available from the corresponding author on reasonable request.

\section{Declarations}

\section{Ethics approval and consent to participate}

Ethical approval was given by the institutional ethics committee (IRB ofthe Obstetrics and Gynecology Hospital of Fudan University) and registered at ClinicalResearch Information Service with registration number ChiCTR2100045162. Informedconsent of information collection for research was obtained from all participants.All methods in this retrospective study were carried out in accordance with institutionalguildlines and regulations. The study was performed in accordance with theethical standards of the Declaration of Helsinki (1964) and its subsequentamendments.

\section{Consent for publication}

Informed consent of information collection for research was obtained from all participants. And the institutional review board provided us the consent to publish.

\section{Competing interests \\ We have no competing interests.}

Received: 18 April 2021 Accepted: 1 September 2021

Published online: 22 September 2021

\section{References}

1. Anim-Somuah M, Smyth RM, Cyna AM, Cuthbert A. Epidural versus non-epidural or no analgesia for pain management in labour. Cochrane Database Syst Rev. 2018;5:CD000331.

2. Jones L, Othman M, Dowswell T, Alfirevic Z, Gates S, Newburn M, et al. Pain management for women in labour: an overview of systematic reviews. Cochrane Database Syst Rev. 2012(3):CD009234. https://doi. org/10.1002/14651858.CD009234.pub2.

3. Brownridge P. Treatment options for the relief of pain during childbirth. Drugs. 1991;41(1):69-80. 
4. Tsen LC, Thue B, Datta S, Segal S. Is combined spinal-epidural analgesia associated with more rapid cervical dilation in nulliparous patients when compared with conventional epidural analgesia? Anesthesiology. 1999;91(4):920-5.

5. Willdeck-Lund G, Lindmark G, Nilsson BA. Effect of segmental epidural analgesia upon the uterine activity with special reference to the use of different local anaesthetic agents. Acta Anaesthesiol Scand. 1979;23(6):519-28.

6. Kanbara T, Tomoda MK, Sato EF, Ueda W, Manabe M. Lidocaine inhibits priming and protein tyrosine phosphorylation of human peripheral neutrophils. Biochem Pharmacol. 1993;45(8):1593-8.

7. Carvalho B, Clark DJ, Yeomans DC, Angst MS. Continuous subcutaneous instillation of bupivacaine compared to saline reduces interleukin 10 and increases substance $P$ in surgical wounds after cesarean delivery. Anesth Analg. 2010;111(6):1452-9.

8. Werdehausen R, Braun S, Fazeli S, Hermanns H, Hollmann MW, Bauer I, et al. Lipophilicity but not stereospecificity is a major determinant of local anaesthetic-induced cytotoxicity in human T-lymphoma cells. Eur J Anaesthesiol. 2012;29(1):35-41.

9. Ngan Kee WD, Khaw KS, Ng FF, Ng KK, So R, Lee A. Synergistic interaction between fentanyl and bupivacaine given intrathecally for labor analgesia. Anesthesiology. 2014;120(5):1126-36.

10. Wang F, Shen X, Guo X, Peng Y, Gu X, Labor Analgesia Examining G. Epidural analgesia in the latent phase of labor and the risk of cesarean delivery: a five-year randomized controlled trial. Anesthesiology. 2009;111(4):871-80.

11. Li B, Wang H, Gao C. Bupivacaine in combination with fentanyl or sufentanil in epidural/intrathecal analgesia for labor: a meta-analysis. J Clin Pharmacol. 2015:55(5):584-91.

12. Beilin $Y$, Halpern S. Focused review: ropivacaine versus bupivacaine for epidural labor analgesia. Anesth Analg. 2010:111(2):482-7.

13. Boulier V, Gomis P, Lautner C, Visseaux H, Palot M, Malinovsky JM. Minimum local analgesic concentrations of ropivacaine and levobupivacaine with sufentanil for epidural analgesia in labour. Int J Obstet Anesth. 2009;18(3):226-30.

14. Debon R, Allaouchiche B, Duflo F, Boselli E, Chassard D. The analgesic effect of sufentanil combined with ropivacaine $0.2 \%$ for labor analgesia: a comparison of three sufentanil doses. Anesth Analg. 2001;92(1):180-3.
15. Cousins MJ, Mather LE. Intrathecal and epidural administration of opioids. Anesthesiology. 1984;61(3):276-310.

16. Zondag DC, Gross MM, Grylka-Baeschlin S, Poat A, Petersen A. The dynamics of epidural and opioid analgesia during labour. Arch Gynecol Obstet. 2016;294(5):967-77.

17. Hosokawa Y, Morisaki H, Nakatsuka I, Hashiguchi S, Miyakoshi K, Tanaka M, et al. Retrospective evaluation of intravenous fentanyl patient-controlled analgesia during labor. J Anesth. 2012;26(2):219-24.

18. Sivalingam T, Pleuvry BJ. Actions of morphine, pethidine and pentazocine on the oestrus and pregnant rat uterus in vitro. Br J Anaesth. 1985;57(4):430-3.

19. Fazackerley J, Pleuvry BJ. Stimulant action of pethidine on the pregnant rat uterus in-vitro. J Pharm Pharmacol. 1987;39(6):491-2.

20. Yoo KY, Lee J, Kim HS, Jeong SW. The effects of opioids on isolated human pregnant uterine muscles. Anesth Analg. 2001;92(4):1006-9.

21. Wang X, Xu S, Qin X, Li X, Feng SW, Liu Y, et al. Comparison between the use of ropivacaine alone and ropivacaine with sufentanil in epidural labor analgesia. Medicine (Baltimore). 2015;94(43):e1882.

22. Wang K, Cao L, Deng Q, Sun LQ, Gu TY, Song J, et al. The effects of epidural/spinal opioids in labour analgesia on neonatal outcomes: a meta-analysis of randomized controlled trials. Can J Anaesth. 2014;61(8):695-709.

23. Cicarelli DD, Silva RV, Frerichs E, Pagnocca ML. Combined spinalepidural for labor analgesia: does the addition of sufentanil to the local anesthetic influence apgar scores of the newborns? Rev Bras Anestesiol. 2007:57(3):272-9.

24. Zhang T, Yu Y, Zhang W, Zhu J. Comparison of dexmedetomidine and sufentanil as adjuvants to local anesthetic for epidural labor analgesia: a randomized controlled trial. Drug Des Devel Ther. 2019;13:1171-5.

\section{Publisher's Note}

Springer Nature remains neutral with regard to jurisdictional claims in published maps and institutional affiliations.

Ready to submit your research? Choose BMC and benefit from:

- fast, convenient online submission

- thorough peer review by experienced researchers in your field

- rapid publication on acceptance

- support for research data, including large and complex data types

- gold Open Access which fosters wider collaboration and increased citations

- maximum visibility for your research: over 100M website views per year

At $B M C$, research is always in progress.

Learn more biomedcentral.com/submissions 